\title{
Work environment in the wheat mills of Punjab, India
}

\author{
Indu Rawat* and Nilesh Gaikwad
}

The present study was conducted on workers in the wheat mills of Punjab, India. They work for 8-12 h or more daily, during which they face two predominant problems, namely noise and dust. Severe hearing damage and deafness can result due to high noise of the machines in the mills for such prolonged period. Likewise, flour dust during milling and packing operations is dangerous. The present study was conducted to assess the noise levels and dust concentration in wheat milling units at various locations in Punjab. High noise in the flour mills was due to the use of a single power source for running a number of machines and consequent use of long flat belt drive to run them, absence of an electric motor enclosure, poor machine maintenance and inadequate acoustic design of the working zone of the milling units. In case of dust hazard, hopper and flour collection area had higher levels of dust concentration in the milling units.

Keywords: Agro-processing, dust, noise, wheat mills, work environment.

WHEAT (Triticum spp.) is the second most important cereal crop in India. The country is the third largest producer of wheat, with an annual production of 92.29 million tonnes (mt) in 2015-16. The national food security emphasizes on wheat because it provides more than $50 \%$ of the calories to the people who are mainly dependent on it. Wheat is consumed mainly in the form of atta (whole meal), maida (white flour), suji (coarse semolina) and rawa (fine semolina) making chapati, poori, bread, biscuits, etc. The industrial uses of wheat include bread and bakery, adhesives, coatings, polymers and resins, cosmetics, paper and pharmaceuticals, etc. Among the abovementioned products, wheat milling into flour for chapati is predominant. Wheat milling is a crucial unit operation carried out before the preparation of wheat-based products. Estimates revealed that over $65 \%$ of the country's total wheat production is used for atta and further for chapati preparation ${ }^{1}$. The other major consumer of wheat flour is the bread and biscuit industry with annual production of 3.75 and $1.95 \mathrm{mt}$ respectively. According to an estimate, there were about 27 lakh atta $(7.5-10 \mathrm{~kW}$ rating) and 812 roller flour mills in the country in year 1998-99 (ref. 2).

The unorganized wheat milling industry in India poses hazardous work environment for the workers. Noise emitted from the industries is usually considered nuisance from the point of view of environmental health and safety, because prolonged exposure can cause permanent

Indu Rawat is in the ICAR-Indian Institute of Soil and Water Conservation, Dehradun 248 195, India and Nilesh Gaikwad is in the ICARNational Research Centre on Pomegranate, Solapur 413 255, India.

*For correspondence. (e-mail: rawat.indu15@gmail.com) hearing damage. It was reported that one-sixth of adults are affected with some degree of physiological hearing impairment due to the ever increasing mills ${ }^{3}$ and $16 \%$ of the hearing loss is due to excessive exposure to industrial noise ${ }^{4}$. Hearing can be affected with exposure to average noise level exceeding $80 \mathrm{dBA}$ over an $8 \mathrm{~h}$ working day. Different countries around the world have set the limits of exposure to noise at the workplace. The Occupational Safety and Health Administration (OSHA) and National Institute for Occupational Safety and Health (NIOSH) standards are most acceptable. The exposure limit prescribed by OSHA is $90 \mathrm{dBA}$ for $8 \mathrm{~h}$ /day and that of $\mathrm{NIOSH}$ is $85 \mathrm{dBA}$. Noise not only causes hearing imbalance (after long-term exposure of over $85 \mathrm{dBA}$, exposure action value), but it also increases stress and raises systolic blood pressure.

As there is no proper follow-up to provide protection to workers from noise pollution, it is considered as a routine and indispensable part of the work environment ${ }^{5}$. The source of noise in agro-processing industries such as wheat milling units is mainly due to the power source (motor/engines), power transmission mechanisms (belt and pulley, gear and chain arrangement), material conveyors (bucket elevators, chain conveyors and screw conveyors) and processing equipment.

The assessment of noise levels in the wheat milling units at different locations is important where complex noise sources are present and to know whether noise levels exceed the permissible exposure limits. While managing noise pollution in the processing units, the first step is to assess the sound levels at different locations. This will help in quantifying the amount of noise to which the workers are exposed to identify the noise 
sources, develop noise control strategies and determine appropriate hearing protection needs.

Another important parameter causing occupational health hazards among workers of wheat milling units is dust. As defined by Calvert ${ }^{6}$, dust consists of 'small, dry and solid particles projected into the air by natural forces, like wind, volcanic eruption, and by mechanical or manmade processes such as crushing, grinding, milling, drilling, demolition, shovelling, conveying, screening, bagging, and sweeping'. Dust particles are usually in the size range $1-100 \mu \mathrm{m}$ in diameter, and they settle slowly with gravity. According to the International Organization for Standardization (ISO, Geneva), dust consists of 'small solid particles, conventionally taken as those particles below $75 \mu \mathrm{m}$ in diameter, which settle out under their own weight but which may remain suspended for some time'.

According to particle size, dust may be categorized into inhalable dust, thoracic dust and respirable dust. The American Conference of Governmental Industrial Hygienists (ACGIH), ISO, and the European Standards Organization (CEN) have reached an agreement on definitions of the inhalable, thoracic and respirable fractions $^{7-10}$. Inhalable particulate fraction is a fraction of the dust cloud that can be inhaled through the nose or mouth. Thoracic particulate fraction can penetrate the head airways and enter the lung airways. Respirable particulate fraction consists of inhaled airborne particles that can penetrate beyond the terminal bronchioles and enter into the gas-exchange region of the lungs. According to ACGIH, inhalable dust is less than $100 \mu \mathrm{m}$ in size. According to OSHA, respirable dust is less than $3.5 \mu \mathrm{m}$ in size and less than $4 \mu \mathrm{m}$ according to $\mathrm{ACGIH}^{11}$.

The respiratory symptoms as a result of dust exposure are associated with impairment of lung function. Some minor problems are caused by irritant dust and some respirable dust fractions can damage the lung tissues. Flour dust, an asthamagen, is known to cause allergic rhinitis, sensitization, and occupational asthma amongst mill workers. Flour dust can act as an irritant and may produce short-term symptoms related to eye, nasal and respiratory system, or it may aggravate an asthma attack in individuals with already existing diseases.

According to OSHA, gravimetrically analysed dust concentration should not exceed $10 \mathrm{mg} / \mathrm{m}^{3}$ and respirable dust particles should be below $5 \mathrm{mg} / \mathrm{m}^{3}$. According to the ACGIH standards, total concentration of dust should not exceed $10 \mathrm{mg} / \mathrm{m}^{3}$ (inhalable fraction) and respirable particles must be below $3 \mathrm{mg} / \mathrm{m}^{3}$. The epidemiological analysis revealed that even low concentration of inhalable flour dust (below $0.5 \mathrm{mg} / \mathrm{m}^{3}$ ) can cause sensitization and occupational airways diseases among workers. However, the possibility of sensitization and symptoms development increases with increasing exposure ${ }^{12-15}$.

Any unautomated and non-enclosed portions of the process, especially during receiving, packaging and final transfer can lead to exposure of significant grain dust and flour. Mill workers, including maintenance personnel are primarily affected by flour dust during flour milling and packing operations. The unorganized wheat milling industry in India poses hazardous work environment for these workers. The grain transportation, feeding, flour collection and packaging are carried out manually and are uncovered, thus leading to high dust exposure.

Keeping these facts in mind, the present study was undertaken to assess the noise and dust in the wheat milling units of Punjab, India.

\section{Materials and method}

Fifteen wheat milling units located in various parts of Ludhiana, Punjab, were surveyed. Information regarding output capacity, size of the power source, maintenance condition of the machines and workroom configurations was gathered through enquiry with the owners of the flour mills and personal observations.

As far as unit operations in wheat milling units are concerned, first wheat is received through trucks and temporarily stored in bulk storage structure. Before conveying it to the stone mills (atta chakkis), debraning of wheat is done. Wheat is then fed into the hopper, either manually or automatically. Manually it is fed through bags or scoops by the workers, whereas automatic operation is done by bucket elevators. After milling operation, the bran layer is separated from the flour obtained by a vibrating screen. The flour obtained is collected in woven sacks, weighed and packed for delivery. Generally, each machine is operated with an individual electric motor. Otherwise all the machines may be operated through a single flat belt drive from a long shaft coupled to an electric motor.

The normal working hours of the flour mills vary from 8 to $12 \mathrm{~h}$. During the study period, relative humidity, average temperature and air velocity in the workrooms of the mills were recorded.

The guidelines of the Canadian Centre for Occupational Health and Safety (CCOHS) were followed for layout construction during the noise and dust survey. A layout showing the location of various machines and workers in the mill was prepared. Grids of specific size (i.e. $0.5 \mathrm{~m} \times 0.5 \mathrm{~m}, 1 \mathrm{~m} \times 1 \mathrm{~m}, 2 \mathrm{~m} \times 2 \mathrm{~m}$ ) were made on the layout to get the representative data for the units. The dimensions of doors, windows and ventilators were also noted.

A sound-level meter (SLM; model SL 4001) was used to record noise levels which were held at arm's length and about $1.5 \mathrm{~m}$ above the floor so that noise is not obstructed with any object. The SLM was directed towards the nearby noisy source. At each grid point, the SPL in weighing scale ' $A$ ' was recorded for $30 \mathrm{sec}$ and data were collected. The floor area in the mills, where sound pressure level (SPL) was beyond $85 \mathrm{dBA}$, 
was identified to determine the causes of high levels of noise.

$$
\begin{aligned}
& T(\min )=\left[480 / 2^{(L-85) / 3}\right]-(\mathrm{NIOSH}), \\
& T(\min )=\left[8 / 2^{(L-90) / 5}\right]-(\mathrm{OSHA}) .
\end{aligned}
$$

Maximum exposure time limit (min) according to NIOSH and OSHA was calculated for each wheat milling unit using the above formulae. $L$ denotes the sound pressure level in sound level meter.

Measurement of dust concentration was made using the Haz Dust Sampler (EPAM 5000). At every grid point, dust concentration was noted with 2 min intervals. The distribution of dust particle size during the above operation was also studied by measuring the mass concentration for particulate matter (PM) 1, PM 2.5 and PM 10, based on the mass concentration of dust particles with diameter less than $1,2.5$ and $10 \mu \mathrm{m}$. This study was conducted to characterize potential exposure during feeding, milling and flour collection operation. The measured dust levels were compared with the standard exposure limits. The relevant exposure standards are the OSHA PEL and ACGIH threshold limit value (TLV) for particulate not otherwise classified (PNOC).

\section{Results}

Table 1 provides general information about flour mills. Questionnaire-based data were collected from the workers of wheat mills regarding working hours, type of shift, work-related illnesses, health hazards, etc. The environmental parameters like temperature, humidity, noise and dust were studied with regard to wheat mills. During the noise and dust survey, guidelines of CCOHS were followed. Layout showing location of various machines

Table 1. General information regarding the units

\begin{tabular}{ccccc}
\hline Units & Workers & $\begin{array}{c}\text { Capacity } \\
(\mathrm{q} / \text { day })\end{array}$ & $\begin{array}{c}\text { Engine } \\
(\mathrm{hp})\end{array}$ & $\begin{array}{c}\text { Average milling } \\
\text { time (h/day) }\end{array}$ \\
\hline 1 & 3 & 20 & 20 & 8 \\
2 & 4 & 15 & 45 & 8 \\
3 & 6 & 30 & 95 & 12 \\
4 & 4 & 25 & 90 & 8 \\
5 & 5 & 30 & 95 & 10 \\
6 & 4 & 20 & 90 & 12 \\
7 & 4 & 25 & 45 & 8 \\
8 & 6 & 20 & 45 & 12 \\
9 & 4 & 20 & 90 & 12 \\
10 & 4 & 25 & 90 & 12 \\
11 & 4 & 20 & 90 & 12 \\
12 & 5 & 20 & 90 & 12 \\
13 & 4 & 20 & 90 & 12 \\
14 & 4 & 25 & 90 & \\
15 & 4 & 25 & 90 & \\
Total $(A)$ & 65 & & & \\
\hline
\end{tabular}

and workers in the mills was also prepared. A grid of specific size (i.e. $0.5,1$ and $2 \mathrm{~m}^{2}$ ) was made on the layout based on the size of the unit and to get the representative data for the unit.

The environmental conditions, viz. average temperature, relative humidity, air velocity and ambient noise during the study period were evaluated (Table 2). The data on noise sources for all the 15 units were elaborative. Table 3 shows the sound generated by different sources as measured at different grid points in the vicinity of the noise source in unit 1. The corresponding maximum exposure limits as recommended by $\mathrm{NIOSH}$ and OSHA are also shown. The highest sound level was generated at the power transmission unit varying in range from 92.2 to $98.5 \mathrm{dBA}$, with the average sound intensity of $95.1 \mathrm{dBA}$ which is highest among all noise sources, followed by motor, wheat milling machine, weighing balance, wheat storage section and flour bags storage section. Power transmission unit caused the highest sound intensity due to improper power transmission mechanism. Sound generated by the wheat milling machine was due to milling action of the stone mills.

Flour dust is generally classified as PNOC, and the exposure limit is expressed as 10 or $15 \mathrm{mg} / \mathrm{m}^{3}$. However, flour dust is seen as a complex mixture of many components, inducing sensitization and respiratory symptoms at much lower levels. To avoid dust sensitivity, it is suggested to have flour dust exposure below $10 \mathrm{mg} / \mathrm{m}^{3}$ to prevent sensitization. Houba et al. ${ }^{15}$ reported a level of $0.5 \mathrm{mg} / \mathrm{m}^{3}$ inhalable dust to prevent or at least minimize the prevalence of wheat flour sensitization. To protect against sensitization and other respiratory symptoms, ACGIH recommended a TLV-time weighted average (TWA) of $0.5 \mathrm{mg} / \mathrm{m}^{3}$ for occupational exposure to inhalable flour dust.

Table 4 shows the respirable, thoracic and inhalable or total suspended particulates (TSP) at different locations in unit 1. PM 1 and PM 2.5 indicate respirable fraction

Table 2. Environmental conditions inside the units

\begin{tabular}{rcccc}
\hline Units & $\begin{array}{c}\text { Temperature } \\
\left({ }^{\circ} \mathrm{C}\right)\end{array}$ & $\begin{array}{c}\text { Humidity } \\
(\%)\end{array}$ & $\begin{array}{c}\text { Air velocity } \\
(\mathrm{m} / \mathrm{s})\end{array}$ & $\begin{array}{c}\text { Ambient noise } \\
(\mathrm{dB})\end{array}$ \\
\hline 1 & 33.1 & 63 & 4.6 & 67.1 \\
2 & 36.6 & 59 & 4.6 & 68 \\
3 & 31.9 & 82 & 5.3 & 69 \\
4 & 30 & 54 & 4.6 & 66.9 \\
5 & 33.4 & 80 & 4.5 & 66 \\
6 & 33 & 60 & 4.2 & 67 \\
7 & 32 & 55 & 4.6 & 66 \\
8 & 31 & 80 & 5 & 63 \\
9 & 30 & 59 & 5.5 & 64 \\
10 & 35 & 81 & 5.9 & 56 \\
11 & 35 & 66 & 5.6 & 70 \\
12 & 36 & 71 & 4.9 & 71 \\
13 & 33 & 62 & 4.0 & 75 \\
14 & 30 & 59 & 5.3 & 62 \\
15 & 31 & 79 & 5.5 & 63 \\
\hline
\end{tabular}


Table 3. Sound Intensity related to different work units and corresponding maximum exposure limit according to NIOSH and OSHA

\begin{tabular}{|c|c|c|c|c|c|}
\hline Noise source & $\begin{array}{l}\text { Grid point } \\
\text { location }\end{array}$ & $\begin{array}{c}\text { Sound } \\
\text { intensity }(\mathrm{dBA})\end{array}$ & $\begin{array}{l}\text { Average sound } \\
\text { intensity }(\mathrm{dBA})\end{array}$ & $\begin{array}{l}\text { NIOSH maximum } \\
\text { exposure limit (h) }\end{array}$ & $\begin{array}{l}\text { OSHA maximum } \\
\text { exposure limit }(\mathrm{h})\end{array}$ \\
\hline \multirow[t]{9}{*}{ Milling machine } & 21 & 90.3 & 91.4 & 2.35 & 7.67 \\
\hline & 22 & 87.9 & & 4.09 & 10.7 \\
\hline & 23 & 88.2 & & 3.81 & 10.26 \\
\hline & 26 & 88.8 & & 3.32 & 9.44 \\
\hline & 27 & 94.5 & & 0.89 & 4.28 \\
\hline & 28 & 86.5 & & 5.65 & 12.99 \\
\hline & 31 & 93.6 & & 1.09 & 4.85 \\
\hline & 32 & 98.5 & & 0.35 & 2.46 \\
\hline & 33 & 94.3 & & 0.93 & 4.4 \\
\hline \multirow[t]{4}{*}{ Motor } & 38 & 92.2 & 92.3 & 1.51 & 5.89 \\
\hline & 39 & 89 & & 3.17 & 9.18 \\
\hline & 43 & 95.5 & & 0.7 & 3.73 \\
\hline & 44 & 92.8 & & 1.31 & 5.42 \\
\hline \multirow[t]{5}{*}{ Power transmission unit } & 32 & 98.5 & 95.1 & 0.35 & 2.46 \\
\hline & 33 & 94.3 & & 0.93 & 4.4 \\
\hline & 37 & 96.1 & & 0.61 & 3.43 \\
\hline & 38 & 92.2 & & 1.51 & 5.89 \\
\hline & 42 & 94.5 & & 0.89 & 4.28 \\
\hline Weighing balance & 14 & 82.6 & & 13.92 & 22.31 \\
\hline \multirow[t]{2}{*}{ Wheat storage section } & 11 & 90 & 89.5 & 2.51 & 8 \\
\hline & 16 & 89 & & 3.17 & 9.18 \\
\hline \multirow[t]{2}{*}{ Flour bags storage section } & 1 & 81.8 & 82.6 & 16.75 & 24.93 \\
\hline & 6 & 83.4 & & 11.57 & 19.97 \\
\hline
\end{tabular}

and PM 10 indicates thoracic fraction. The maximum, minimum and TWA of respirable, thoracic and inhalable fractions are also shown in the table.

At some points, TSP near all the workplaces was above the recommended value of $0.5 \mathrm{mg} / \mathrm{m}^{3}$ (ref. 11). The highest measured TSP-TWA value was $17.941 \mathrm{mg} / \mathrm{m}^{3}$ at the wheat feeding section (location 17), much greater than the recommended limit. This might be due to dust dispersed during the task of feeding wheat to the hopper. TSP-TWA values at the points $22,26,27$ and 28 which were in the vicinity of the milling machine were found to be $2.522,1.052,1.067$ and $1.056 \mathrm{mg} / \mathrm{m}^{3}$ respectively, which were also more than the recommended limit. This may be because these points are near the hopper and vibrating screen where dust gets suspended due to pouring of wheat, and to and fro motion of the screen respectively. Near the wheat storage section at the locations 11 and 16, the TSP values were 6.568 and $7.910 \mathrm{mg} / \mathrm{m}^{3}$, which may be because these points were nearer the flour collection area and milling machine. Flour collection area represented by location 18 had TSP concentration of $2.125 \mathrm{mg} / \mathrm{m}^{3}$. This may be due to collection of flour by scoop and filling it in the bags in this area. TSP value near the weighing balance (location 14) was 0.532 $\mathrm{mg} / \mathrm{m}^{3}$, which was found higher due to flour compensation during weighing process and also due to dust emitted by the bagging operation near the balance.
Data on dust in other units were found to be almost similar.

\section{Conclusion}

The noise survey in the selected 15 wheat milling units of Ludhiana revealed that the workers in these units are exposed to high sound levels, which would have detrimental effects on their health, as the working zone had SPL more than $85 \mathrm{dBA}$ (permissible limit by NIOSH) in locations where they were engaged most of the time. The normal working period in the wheat milling units was $8-12 \mathrm{~h} /$ day. The predominant noise sources in these units were the power transmission mechanism, electric motor, wheat milling machines (stone mills) and debraning units. The high noise in the flour mills was due to the use of a single power source for running a number of machines, consequent use of long flat belt drive to run them, absence of an electric motor enclosure, poor machine maintenance and inadequate acoustic design of the working zone of the milling units. The use of personal protection measures such as ear plugs, mufflers, etc. was lacking.

A TLV of $0.5 \mathrm{mg} / \mathrm{m}^{3}$ is recommended by the ACGIH for TSP. All the locations where the workers were present had higher dust concentration than the recommended 


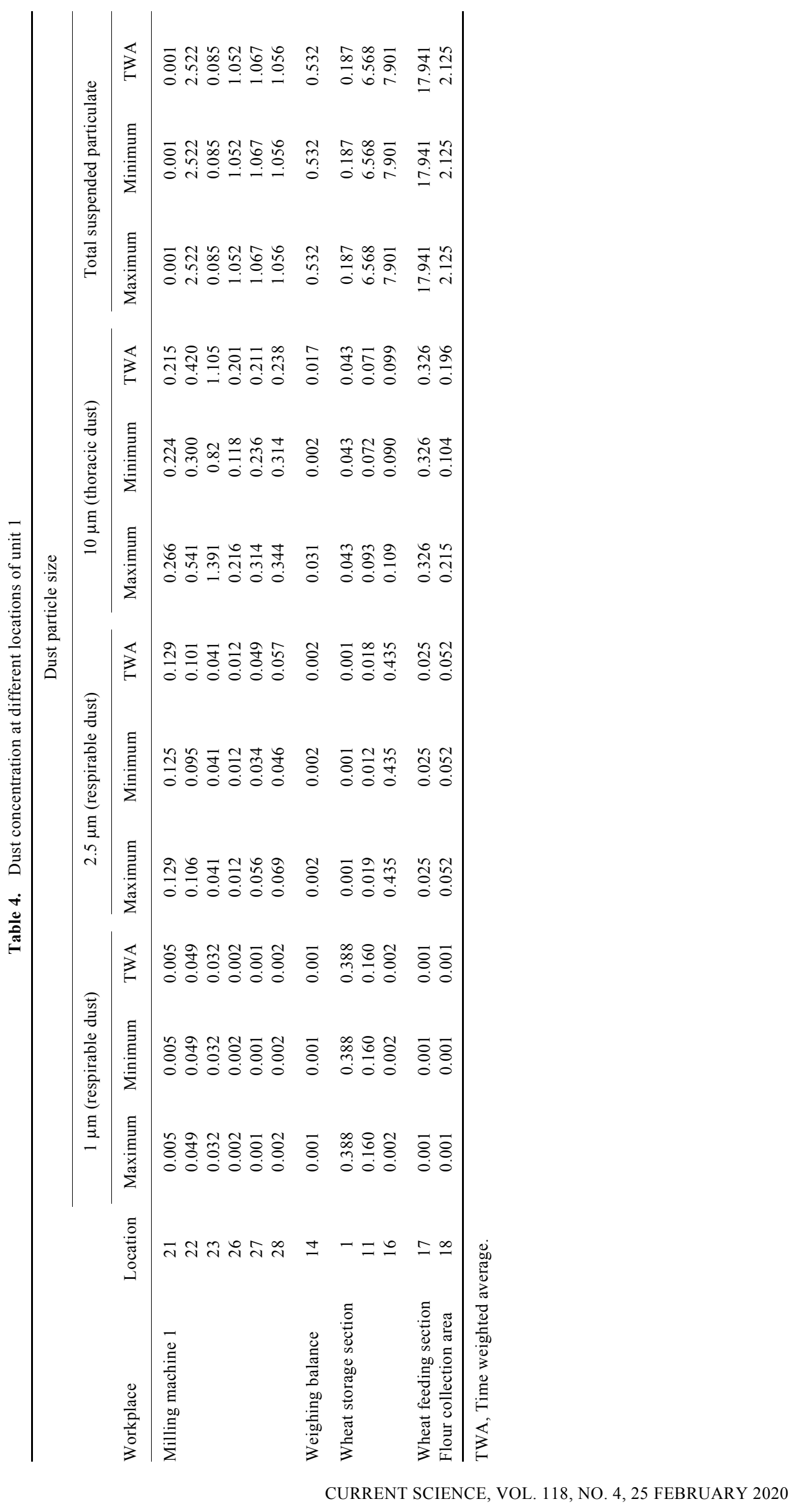


value. The two locations in the wheat milling units where workers spend considerable amount of time are the hopper and flour collection area. Studies reveal that these two points have higher level of dust concentration in the milling units. In most units, the concentration of TSPTWA near the wheat feeding station was much greater than the corresponding respirable and thoracic TWA. But at the flour collection area, the TSP-TWA concentration was lower compared to the feeding section. This indicates that the larger-sized particles of diameter 10-100 $\mu \mathrm{m}$ that come along with wheat are suspended in the feeding area. Moreover, the wheat flour collection area has smaller size dust particles of diameter less than $10 \mu \mathrm{m}$. The minimum TWA of dust concentration was found at the corners, which might be due to settlement of particles on the walls. Inhalation of flour dust can produce allergic reaction, shortness of breath, eye problems and chronic respiratory disorders, including sensitization and asthma. It can also induce a specific hypersensitive state in individuals, and provoke an asthmatic response in those previously sensitized.

\section{Recommendations}

- Personal protective equipment like ear plugs should be provided to the workers.

- In all the milling units, preventive maintenance of machines needs to be given due importance.

- If noise is unavoidable, then working hours should be reduced as recommended by NIOSH and OSHA.

- Special attention should be given to the emission sources of dust particulates and diffusion of the emitted flour dust should be controlled.

- Pre-employment and periodic medical surveillance tests should be mandatory for all the workers. The use of personal protective equipment like face masks is also recommended to provide additional protection.

- The ventilation system should be improved in order to reduce build-up of air contaminant levels.

- In high dust concentration areas, the working hours should be reduced.
1. Baisya, R. K., Processed food industry, 2004; http://www. pfionline.com/index.php/columns/recent-development/89-bakeryindustry-in india-a-category-review.

2. Kachru, R. P., Status of farm mechanization in India. In AgroProcessing Industries in India-Growth, Status and Prospects, 2000; http://agricoop.nic.in/Farm\%20Mech.\%20PDF/05024-06.pdf.

3. Anon., The economic impact and cost of hearing loss in Australia. In National Health Report of Access Economics, 2006; http://www.audiology.asn.au/pdf/listenhearfinal.pdf

4. Nelson, D. I., Nelson, R. Y., Concha-Barrientos, M. and Fingerhut, M., The global burden of occupational noise-induced hearing loss. Am. J. Ind. Med., 2005, 48, 446-458.

5. Bhat, S., A few reflections of noise pollution: issues and concerns in urban India, 2003; http://www.ncbi.nlm.nih.gov/pmc/articles/ PMC2796776

6. Calvert, J. G., Glossary of atmospheric chemistry terms. Pure Appl. Chem., 1990, 62(11), 2167-2219.

7. Bioaerosols: assessment and control. In American Conference of Governmental Industrial Hygienists, Cincinnati, OH, USA, 1999.

8. ISO, Air quality-particle size fraction definitions for healthrelated sampling. ISO Standard 7708. International Organization for Standardization, Geneva, Switzerland, 1995.

9. Anon., Workplace atmospheres - size fraction definitions for measurement of airborne particles, European Standard EN 481, European Standardization Committee, Brussels, Belgium, 1993.

10. Anon., Human respiratory tract model for radiological protection. International Commission on Radiological Protection Publication 66. Elsevier Science Ltd, Oxford, UK. Annals of the ICRP 24(13), 1994.

11. Documentation of the threshold limit values and biological exposure Indices - Appendix B, American Conference of Governmental Industrial Hygienists, Cincinnati, OH, USA, 2004.

12. Heederik, D. and Houba, R., An exploratory quantitative risk assessment for high molecular weight sensitizers: wheat flour. Ann. Occup. Hyg., 2001, 45(3), 175-185.

13. Cullinan, P. et al., Allergen and dust exposure as determinants of work-related symptoms and sensitization in a cohort of flourexposed workers; a case control analysis. Ann. Occup. Hyg., 2001, 45, 97-103.

14. Houba, R., Heederik, D. and Doekes, G., Wheat sensitization and work-related symptoms in the baking industry are preventable, an epidemiologic study. Am. J. Res. Crit. Care Med., 1998, 158, 1499-1503.

15. Houba, R., Heederik, D. J., Doekes, G. and Van, R. P. E., Exposure sensitization relationship for alpha-amylase allergens in the baking industry. Am. J. Respir. Crit. Care Med., 1996, 154, 130-136.

Received 29 March 2019; revised accepted 16 September 2019

doi: $10.18520 / \mathrm{cs} / \mathrm{v} 118 / \mathrm{i} 4 / 526-531$ 